\title{
Perceived Myths and Misconceptions about the Novel COVID-19 Outbreak
}

\author{
Michael Abiola Okunlola ${ }^{a^{*}}$, Emmanuel Lamptey ${ }^{b}$, Ephraim Kumi Senkyire ${ }^{c}$, \\ Serwaa Dorcas ${ }^{\mathrm{b}}$, Benita Aki Dooshima ${ }^{\mathrm{d}}$ \\ ${ }^{a}$ Department of Obstetrics and Gynaecology, University College Hospital/College of Medicine, University of Ibadan, Ibadan, Nigeria. \\ ${ }^{b}$ Institute of Life and Earth Sciences (Including Health and Agriculture), Pan African University, University of Ibadan, Ibadan, Nigeria. \\ ${ }^{c}$ Department of Pediatric Nursing, Cape Coast Teaching Hospital, Ghana. \\ ${ }^{d}$ Benue State University, Makurdi, Nigeria.
}

Received 22 April 2020; Accepted 14 July 2020

\begin{abstract}
The outbreak of the novel Coronavirus (Covid-19) which was first reported in Wuhan, China has now spread globally becoming a matter of international concern. The World Health Organization officially changed their classification of the situation from a Public Health Emergency of International Concern to a Pandemic on March 11, 2020. As the corona virus continues to spread rapidly so do the headline news and a host of misconceptions surrounding the outbreak. This paper investigated and highlighted some of the most common misconceptions surrounding the outbreak of the covid-19. Using a cross-sectional survey method, the study collected and analysed data on these misconceptions and examined factors that influence the levels of these misconceptions. The study identified four top misconceptions respondents believe or agree with. These are; the novel corona virus is deadly $(83.3 \%)$, Hand sanitizers do kill the virus $(67.5 \%)$, face mask offer protection against the virus $(55.8 \%)$ and Drying the hands with hand dryer helps to prevent the virus (44.2\%). However, respondents were able to disagree, identify correctly and debunked certain statements of misconception. These include coronavirus affect only the elderly (95\%), the virus can spread by mosquito bites (87.5\%), antibiotics are effective for treatment (60\%) and homemade remedies can cure the corona virus (54. 2\%). Factors such as employment status and the relatedness of respondent's occupation to Human Health were found to influence some of these misconceptions. Exploring these misconceptions keep the general public fully educated and informed about the facts of the outbreak as well as avoiding making up these misconceptions to protect themselves.
\end{abstract}

Keywords: COVID-19 Outbreak; Myths and Misconceptions; West Africa.

\section{Introduction}

The Corona virus mainly affects the respiratory system. This virus is part of the corona family which include severe acute respiratory syndrome (SARS)-COV and the Middle East respiratory syndrome (MERS)-COV [1]. These infectious diseases are all great threat to public safety and Health [2].

The covid-19 started manifesting when a cluster of patients were admitted to the hospital in Wuhan China. These patients were exhibiting signs and symptoms of pneumonia. The causation was first linked to the sea food and live animal market in Wuhan, Huabei Province of China [3].

The origin and the onset of the COVID-19 was sequential, around the middle of December 2020, five patients were

* Corresponding author: biolaokunlola@gmail.com

doI http://dx.doi.org/10.28991/SciMedJ-2020-0203-1

$>$ This is an open access article under the CC-BY license (https://creativecommons.org/licenses/by/4.0/).

(C) Authors retain all copyrights. 
hospitalized with symptoms suggestive of acute respiratory distress syndrome and one of them died [4]. In the next year which was January 2020, COVID-19 was confirmed in 41 patients through laboratory testing. Progressively, the disease started spreading sharply and as at 22 January 2020, a total of 571 cases of the new virus have been confirmed in 25 provinces across China [5].

In 25 January 2020, the total number of cases confirmed in China had reached a total of 1975 with 56 deaths [5]. This estimates showed that the COVID-19 was a fast spreading. As of January 30 2020, all reports indicate that 90 cases have been spread and confirmed in nearby Asia countries such as Taiwan, Thailand, Vietnam, Malaysia, Japan, South Korea etc. and even the United States of America [6].

When the outbreak of the COVID-19 was well known and investigated, it was documented that asymptomatic carriers can transmit the virus via person to person contact [7]. This was not the only observation; it was evident that patients with Acute Respiratory Distress confirmed with the COVID-19 had no signs of pneumonia when examined on chest computed Tomography. Whereas patients with pneumonia defined as COVID-19 show both respiratory and pneumonia features on chest radiography. The disease also leads to critical conditions like respiratory and organ failure [8].

Initially, COVID-19 cases were mostly adults in their late forties. This finding was supported by a research done in 31 provinces of china with 1099 patients from 522 hospitals. The median age of this study was 47 years and the symptoms of ARD and pneumonia were both common in all patients [9]. Further study was done in South Korea by Ryi et al. (2020) and they found that the age ranges of 15 cases were between 25 and 62 years. Several studies came to the conclusion that most COVID-19 patients are middle aged adults, men easily contract the disease and hospital admissions are also responsible for the spread of the virus. According to the China Centre of Disease Control (CDC) reports, children aged 0-14 only form 0.9\% of COVID-19 cases and there is no evidence that it attacks people of Asian Descent more.

Currently, there are no specific vaccines against the COVID-19. Existing antiviral drugs have been used so far for the management of the COVID-19. These include the following drugs $75 \mathrm{mg}$ oseltamivir, $500 \mathrm{mg}$ lopinavir, $500 \mathrm{mg}$ ritonavir and the intravenous administration of $0.25 \mathrm{~g}$ ganciclovir for 3-14 days. There are studies proving that remdesivir and chloroquine are highly effective in the control of the virus [10]. A study by Colson et al. (2020) show that chloroquine is $50 \%$ effective in controlling the virus [11].

According to researchers, developing a full therapeutic regimen could take a year or more. Compounds like EIDD2801 are still in the process of research although they have high potentials.

The COVID-19 is new to the globe and therapeutics for the condition is not fully clear. Therefore, extensive measures are needed to stop the virus from propagating. These measures must be taken by all people including children, the elderly and health care providers. Disinfection, social distancing and handwashing with soap are required on a routine basis. Physical contact with people and wet contaminated objects should be avoided. In applying measures to control the propagation of the virus, some people believe in certain perceptions which are not correct and truly not preventive in nature. These include using face mask, hand sanitizers and drying the hands with hand dryer helps to prevent the virus etc.

To date (as of $25^{\text {th }}$ March, 2020), China has the highest number of patients with COVID-19 ( $\mathrm{n}=81848$ ) followed by Italy $(n=69176)$, United States $(n=51914)$ and Spain $(n=39673)$ according to the World Health Organization (WHO, 2020). The total number of cases and deaths outside china now outweigh cases within China which is the Epic Centre of the Disease. China has been the epicenter of two pandemic outbreaks endangering the lives of people around the globe. The first was the pandemic of SARS which infected the lives of 8098 Individuals with 774 deaths. This disease started in Guangdong, China and spread to more than 12 countries. All these diseases were believed to have originated from bats [12].

Globally at now (25 March, 2020), there are 167511 confirmed cases with 6606 deaths, four new countries two in Africa, one in Europe and the other one in the Americas have reported cases of COVID-19 in the past 24 hours(WHO, 2020). Estimates projecting from the outbreak of the previous SAR-COV show that the COVID-19 could cost the global economy 30 to 100 Billion US Dollars [13]. The control, early detection and management of cases require accurate knowledge and preventive measures in all areas and communities because the novel COVID-19 is rapidly spreading. Due to the fast spreading nature, the WHO declares the COVID-19 as the sixth public health emergency with international concern. This implies that the virus is propagating globally and coordinated international efforts are required to control it. There is increased dissemination of information across all geographical regions and disciplines through the use of the internet and social Medias. The WHO COVID-19 Incident Management Teams are closely working with partners across all levels to strengthen global response to the Virus. Part of the strategic objectives of the WHO is to address crucial unknowns regarding clinical severity, extent of transmission, treatment options, and to communicate critical risk and event information to all communities countering misinformation. The world health organization is not just battling the virus but also the trolls and conspiracy theorists that push misinformation and 
undermine the outbreak response (Tedros, 2020). However, there remain a considerable number of beliefs, myths and misconceptions that must be addressed. These misconceptions, myths and misunderstandings could be a major constraint militating the achievement of the WHO strategic objectives. This article investigates and highlights these misconceptions, myths and beliefs surrounding the outbreak of novel COVID-19.

\section{Materials and Methods}

To investigate the misconception across West Africa, a quantitative explorative structured questionnaire was designed and created on $9^{\text {th }}$ March, 2020.The survey was developed based on review of relevant literature about the COVID-19 Outbreak from credible sources. Respondents were reached and recruited by posting the survey link to Facebook, groups on Facebook, various Facebooks pages, Instagram, twitter, WhatsApp groups, LinkedIn, reedit and also shared to relatives, contacts and friends across West Africa. These accessible populations then shared and forwarded the survey to their contacts and various groups to keep the survey trending.

All possible online channels and Medias were utilized to get the survey widely distributed. The survey was open for data collection for 3 weeks from $9^{\text {th }}$ March to $29^{\text {th }}$ March, 2020.The survey consists of two main sections, first part demographics characteristic of respondents including respective countries and the second part is about their agreement with statements perceived about the COVID-19 outbreak.

To ensure adequate ethical considerations and validity of the data collected, respondents have to be over the age of 18 years and above to complete the survey. The purpose of study, confidentiality, voluntary nature of the survey and the estimated time it will take to complete the questionnaire were explained to potential respondents. Respondents were also informed that by choosing to access the survey link, they are providing their consent to participate.

Although participants could exist the survey at any point, important questions require a mandatory response in order to proceed to the next item of the survey. A total of 1200 respondents had access to the survey and filled through voluntarily. No sample size calculation method was employed because, the readiness of respondents to make time and use their data in filling through the survey was a major considering factor that determines the number of participants.

Data collected were cleaned (uncompleted responses were deleted), entered into Excel and SPSS version 22 for analysis and frequency calculation. To explore potentials associated factors with their misconceptions, a chi-square was computed with significance level stated as $\mathrm{p}$ value. The confidence level was $95 \%$ and statistical significance set to be $\mathrm{p}<0.05$.

\section{Results}

This chapter analyses the responses from the participant of the study. These are represented in tables for clarity and their interpretation follows thereafter.

Table 1. Demographic characteristics of Respondents

\begin{tabular}{lcc}
\hline Characteristics & Number (n) & Percentage (\%) \\
\hline Age & 20 & 1.7 \\
$18-20$ & 620 & 51.7 \\
$21-30$ & 480 & 40.0 \\
$31-40$ & 70 & 5.8 \\
$41-50$ & 10 & 0.8 \\
51 and above & & \\
Gender & 540 & \\
Female & 660 & 45 \\
Male & & 55 \\
Marital Status & 430 & \\
Married & 720 & 35.8 \\
Single & 50 & 60.0 \\
Cohabitation/Relationship & & 4.2 \\
Religion & & \\
Christians & 1070 & 89.2 \\
Muslims & 130 & 10.8 \\
Traditional/Others & 0.0 & 0.0 \\
Educational level & & \\
Elementary/Junior/High School & 30 & 2.5 \\
Undergraduate & 790 & 65.8 \\
Postgraduate & 380 & 31.7 \\
& &
\end{tabular}




\begin{tabular}{lcc} 
Occupational Status & & \\
Employed & 920 & 76.7 \\
Unemployed & 280 & 23.3 \\
Country & & \\
Ghana & 629 & 52.4 \\
Nigeria & 333 & 27.7 \\
Benin Republic & 69 & 5.7 \\
Gambia & 46 & 3.8 \\
Senegal & 38 & 3.1 \\
Sierra Leone & 23 & 1.9 \\
Mali & 20 & 1.7 \\
Liberia & 17 & 1.4 \\
Togo & 15 & 1.2 \\
Ivory Coast & 10 & 0.8 \\
\hline
\end{tabular}

Table 1 represent the socio demographic characteristic of respondents. A total of 1200 people responded, $\mathbf{5 5 . 0 \%}$ (660) were male while the rest $\mathbf{4 5 . 0 \%}$ (540) were females. The age distribution was made up of the following: 18-20 $(1.7 \%) ; 21-30(51.7 \%) ; 31-40(40.0 \%) ; 41-50(5.8 \%)$, and 51 years and above representing $0.8 \%$. Majority of respondents were having undergraduate education $(65.8 \%)$ followed by those with Post graduate education (31.7\%). The least been elementary, junior and high school education (2.5\%). 89.2\% (1070) were Christians and the remaining $10.8 \%$ (130) been Muslims. With occupational status, $76.7 \%$ were employed while $23.3 \%$ were not. The study found that majority of the respondents $\mathbf{( 8 3 . 3 \%}$ ) were worried about the virus been deadly, following this, two-third of the respondents believe that hand sanitizers do kill the virus, then half of the respondents maintain the view that face mask protects against the virus and a little bit less than half agreed that drying the hands with hand dryers help to prevent the virus.

Table 2. Responses to the Statements

\begin{tabular}{lccc}
\hline \multicolumn{1}{c}{ Statements } & Responses (n (\%)) & Neutral (No idea) \\
\hline & \multicolumn{1}{c}{ Agree } & Disagree & $100(8.3 \%)$ \\
\hline 1. Hand Sanitizer does kill corona virus & $810(67.5 \%)$ & $290(24.2 \%)$ & $30(2.5 \%)$ \\
2. Corona Virus only affect the elderly & $30(2.5 \%)$ & $1140(95 \%)$ & $50(4.2 \%)$ \\
3. Face mask protects against the Corona Virus & $670(55.8 \%)$ & $480(40 \%)$ & $490(40.8 \%)$ \\
4. Dogs can get Corona Virus & $400(33.3 \%)$ & $310(25.8 \%)$ & $120(10 \%)$ \\
5. We should be worried about the virus because it is deadly. & $1000(83.3 \%)$ & $80(6.7 \%)$ & $310(25.8 \%)$ \\
6. There is a Vaccine for the Virus & $100(8.3 \%)$ & $790(65.8 \%)$ & $370(30.8 \%)$ \\
7. Homemade remedies can cure the Corona Virus & $190(15.8 \%)$ & $640(53.3 \%)$ & $330(27.5 \%)$ \\
8. The Flu is more dangerous than the Corona Virus & $220(18.3 \%)$ & $650(54.2 \%)$ & $280(23.3 \%)$ \\
9. People of Asian Descent are likely to be infected and spread it & $330(27.5 \%)$ & $590(49.2 \%)$ & $550(45.8 \%)$ \\
10. The corona Virus was deliberately engineered at the Lab & $350(29.2 \%)$ & $300(25 \%)$ & $280(23.3 \%)$ \\
11. The Virus can be transmitted in Chinese food and packages & $310(25.8 \%)$ & $610(50.8 \%)$ & $240(20 \%)$ \\
12. Drying the hands with hand dryer helps to prevent the virus from spreading & $530(44.2 \%)$ & $430(35.8 \%)$ & $220(18.3 \%)$ \\
13. The Virus does not survive in hot and humid weather & $460(38.3 \%)$ & $520(43.3 \%)$ & $120(10 \%)$ \\
14. You can catch the Virus through mosquito bites & $30(2.5 \%)$ & $1050(87.5 \%)$ & $340(28.3 \%)$ \\
15. Antibiotics are effective for treatment & $140(11.7 \%)$ & $720(60 \%)$ & $470(39.2 \%)$ \\
16. Eating Garlic could help fight the Virus & $290(24.2 \%)$ & $440(36.7 \%)$ &
\end{tabular}

Certain demographic factors showed significant changes with some of the misconceptions. Employment and the relatedness of the respondent's occupation to Human Health caused significant changes in six misconceptions as summarized in Table 3. 
Table 3. Factors that could influence the level of these misconceptions

\begin{tabular}{|c|c|c|c|c|c|c|c|c|}
\hline \multirow[t]{2}{*}{ Variable } & \multicolumn{2}{|c|}{ Occupational Status } & \multirow[t]{2}{*}{$\mathbf{X}^{2}$} & \multirow[t]{2}{*}{$P$ value } & \multicolumn{2}{|c|}{$\begin{array}{c}\text { Occupation } \\
\text { related to } \\
\text { Human Health }\end{array}$} & \multirow[t]{2}{*}{$\mathbf{X}^{2}$} & \multirow[t]{2}{*}{$P$ value } \\
\hline & Employed & Unemployed & & & No & Yes & & \\
\hline \multicolumn{9}{|c|}{ 1. Hand Sanitizer does kill Corona virus } \\
\hline Agree & 660 & 150 & & & 270 & 540 & & \\
\hline Disagree & 220 & 70 & 8.57 & 0.01 & 120 & 170 & 0.68 & 0.71 \\
\hline Neutral & 40 & 60 & & & 40 & 60 & & \\
\hline \multicolumn{9}{|c|}{$\begin{array}{l}\text { 2. We should be about the virus } \\
\text { spreading and becoming deadly }\end{array}$} \\
\hline Agree & 780 & 220 & & & 350 & 650 & & \\
\hline Disagree & 80 & 0 & 7.30 & 0.026 & 10 & 70 & 4.56 & 0.102 \\
\hline Neutral & 60 & 60 & & & 70 & 50 & & \\
\hline \multicolumn{9}{|l|}{ 3. Dogs can get Coronavirus } \\
\hline Agree & 310 & 90 & & & 140 & 260 & & \\
\hline Disagree & 260 & 50 & 1.66 & 0.43 & 60 & 250 & 6.30 & 0.043 \\
\hline Neutral & 350 & 140 & & & 230 & 260 & & \\
\hline \multicolumn{9}{|c|}{$\begin{array}{l}\text { 4. The Flu is more dangerous than the } \\
\text { coronavirus }\end{array}$} \\
\hline Agree & 160 & 60 & & & 30 & 190 & & \\
\hline Disagree & 570 & 80 & 11.3 & 0.003 & 250 & 400 & 6.23 & 0.044 \\
\hline Neutral & 190 & 140 & & & 15 & 180 & & \\
\hline \multicolumn{9}{|c|}{$\begin{array}{l}\text { 5. The Virus can be transmitted in } \\
\text { Chinese foods and packages }\end{array}$} \\
\hline Agree & 250 & 60 & & & 70 & 240 & & \\
\hline Disagree & 480 & 130 & 1.62 & 0.443 & 210 & 400 & 6.25 & 0.044 \\
\hline Neutral & 190 & 90 & & & 150 & 130 & & \\
\hline \multicolumn{9}{|c|}{$\begin{array}{l}\text { 6. The virus does not survive in hot/ } \\
\text { humid weather }\end{array}$} \\
\hline Agree & 370 & 90 & & & 130 & 330 & & \\
\hline Disagree & 440 & 80 & 10.9 & 0.004 & 170 & 350 & 6.54 & 0.038 \\
\hline Neutral & 110 & 110 & & & 130 & 90 & & \\
\hline
\end{tabular}

\section{Discussion and Conclusion}

COVID-19 remains pandemic and a public health issue in our respective communities and countries. Myths, misconceptions and misinformations about the outbreak may affect the way the virus can be control at the individual, national and global level.

Addressing these myths and misconceptions is important to protect everyone and those at high risk. The findings of this study reveal that people are aware of some essential facts about the COVID-19.

For instance, respondents were able to identify statements which were not true and disagreed with them. Majority of the respondents know that Corona virus affect all people irrespective of age. Knowing that everyone on planet earth is susceptive to the disease will prompt people to take preventive measures. The spreading of the virus by mosquitoes, availability of vaccines, the flu been more dangerous than the virus and the use of homemade remedies for COVID-19 were other perceptions respondents completely disagree with and they were correct to disagree with these misconceptions. These were summarized in Table 2 above.

On the contrast, People are worried about the virus and are under panic that it is deadly. This suggests the coronavirus outbreak has psychological implications. There is no solid conclusion that the novel COVID-19 is completely deadly. Death rate varies by location, age and presence of co-morbidity in people. There are and still many instances when people who get infected with the virus recover at home without any hospital management and in a number of patients, COVID-19 are deadly. The COVID-19 is mostly dangerous to the elderly and those with preexisting conditions. According to the WHO, as of $5^{\text {th }}$ March 2020, about 3.4\% of reported COVID-19 patients around the world have died. In Africa, there are 3766 confirmed cases with 95 deaths from 25 February to $1^{\text {st }}$ April 2020 (WHO, 2020). Although the covid-19 is fast spreading, people should not be under panic, anxious and believe totally that is highly deadly.

The believe that hand sanitizer does kill the virus is still evident among respondents. It is argued whether hand 
sanitizers do actually control the virus. This must be addressed properly and the right education must be given. Hand sanitizers do control the virus when the level of alcohol is about 60-90\% (Pankhania, 2020). It must be in the right proportion to control the virus. Handwashing with soap and water is the best and the general public must be informed to prioritize this over hand sanitizers.

The use of facemask among the population is still trending, people are tempted to wear mask to feel secured, a little bit more than half of the respondents believe in the use of the face mask for providing protection. Keeping the hand clean and away from sensitive areas like the nose, eyes and eyes is the best (Pankhania, 2020). Facemask should only be worn by health care providers in the healthcare setting. N95 mask blocks $95 \%$ of particles that are 0.3 microns, Corona virus droplets ranges between 0.1 and 0.2 microns, so no protection is guaranteed. Face mask must be worn only in specific areas and must be combined with hand hygiene. People must be educated to wear mask only when they have cough, fever and difficulty breathing. There is no need to wear facemask if these symptoms are absent. Surgical mask worn by most people are not airtight hence no protection. There is no evidence that facemask protects against corona virus.

Lastly, people are still believing that hand dryers help prevent or control the virus. This is not true and does not help at all. Hand drying is recommended only after handwashing. These are the four common misconceptions this study identified and highlighted. In addition, a chi squared test performed to investigate factors that could influence these perceptions showed that the employment status of respondents and the relatedness of their occupation to Human Health had a statistically significant relationship. People who are actively employed going about their daily activities and in health related occupations are well informed, have insight and they make a difference.

In conclusion, this study reveals that people have adequate and accurate information about the COVID-19 outbreak except with few certain misconceptions discussed above. Health authorities and organizations in West Africa should focus on educating people on these identified and highlighted misconceptions.

\section{Acknowledgements}

The authors thank all the participants for their voluntary participation and support.

\section{Declaration of Competing Interest}

The authors declare that they have no known competing financial interests or personal relationships that could have appeared to influence the work reported in this paper.

\section{Ethical Approval}

All procedures performed in studies involving human participants were in accordance with the ethical standards of the National Health Research Ethics Committee (NHREC), Nigeria and with the 1964 Helsinki declaration and its later amendments or comparable ethical standards.

\section{References}

[1] Rothe, C., Schunk, M., Sothmann, P., Bretzel, G., Froeschl, G., Wallrauch, C., Zimmer, T., Thiel, V., Janke, C., Guggemos, W., Seilmaier, M., Drosten, C., Vollmar, P., Zwirglmaier, K., Zange, S., Wölfel, R., \& Hoelscher, M. (2020). Transmission of 2019nCoV Infection from an Asymptomatic Contact in Germany. New England Journal of Medicine, 382(10), 970-971. doi:10.1056/NEJMc2001468.

[2] Chen, H., Guo, J., Wang, C., Luo, F., Yu, X., Zhang, W., Li, J., Zhao, D., Xu, D., Gong, Q., Liao, J., Yang, H., Hou, W., \& Zhang, Y. (2020). Clinical characteristics and intrauterine vertical transmission potential of COVID-19 infection in nine pregnant women: A retrospective review of medical records. The Lancet, 395(10226), 809-815. doi:10.1016/S01406736(20)30360-3.

[3] Li, Q., Guan, X., Wu, P., Wang, X., Zhou, L., Tong, Y., Ren, R., Leung, K. S. M., Lau, E. H. Y., Wong, J. Y., Xing, X., Xiang, N., Wu, Y., Li, C., Chen, Q., Li, D., Liu, T., Zhao, J., Liu, M., .. Feng, Z. (2020). Early Transmission Dynamics in Wuhan, China, of Novel Coronavirus-Infected Pneumonia. New England Journal of Medicine, NEJMoa2001316. doi:10.1056/NEJMoa2001316.

[4] Yu, P., Zhu, J., Zhang, Z., \& Han, Y. (2020). A Familial Cluster of Infection Associated With the 2019 Novel Coronavirus Indicating Possible Person-to-Person Transmission During the Incubation Period. The Journal of Infectious Diseases, jiaa077. doi:10.1093/infdis/jiaa077.

[5] Lee, P.-I., \& Hsueh, P.-R. (2020). Emerging threats from zoonotic coronaviruses-from SARS and MERS to 2019-nCoV. Journal of Microbiology, Immunology and Infection, S1684118220300116. doi:10.1016/j.jmii.2020.02.001. 
[6] Yang, Y., Lu, Q., Liu, M., Wang, Y., Zhang, A., Jalali, N., Dean, N., Longini, I., Halloran, M. E., Xu, B., Zhang, X., Wang, L., Liu, W., \& Fang, L. (2020). Epidemiological and clinical features of the 2019 novel coronavirus outbreak in China [Preprint]. Epidemiology. doi:10.1101/2020.02.10.20021675.

[7] Lai, C.-C., Liu, Y. H., Wang, C.-Y., Wang, Y.-H., Hsueh, S.-C., Yen, M.-Y., Ko, W.-C., \& Hsueh, P.-R. (2020). Asymptomatic carrier state, acute respiratory disease, and pneumonia due to severe acute respiratory syndrome coronavirus 2 (SARS-CoV-2): Facts and myths. Journal of Microbiology, Immunology and Infection, S1684118220300402. doi:10.1016/j.jmii.2020.02.012.

[8] Huang, C., Wang, Y., Li, X., Ren, L., Zhao, J., Hu, Y., Zhang, L., Fan, G., Xu, J., Gu, X., Cheng, Z., Yu, T., Xia, J., Wei, Y., Wu, W., Xie, X., Yin, W., Li, H., Liu, M., ... Cao, B. (2020). Clinical features of patients infected with 2019 novel coronavirus in Wuhan, China. The Lancet, 395(10223), 497-506. doi:10.1016/S0140-6736(20)30183-5.

[9] Wang, D., Hu, B., Hu, C., Zhu, F., Liu, X., Zhang, J., Wang, B., Xiang, H., Cheng, Z., Xiong, Y., Zhao, Y., Li, Y., Wang, X., \& Peng, Z. (2020). Clinical Characteristics of 138 Hospitalized Patients with 2019 Novel Coronavirus-Infected Pneumonia in Wuhan, China. JAMA, 323(11), 1061. doi:10.1001/jama.2020.1585.

[10] Wang, M., Cao, R., Zhang, L., Yang, X., Liu, J., Xu, M., Shi, Z., Hu, Z., Zhong, W., \& Xiao, G. (2020). Remdesivir and chloroquine effectively inhibit the recently emerged novel coronavirus (2019-nCoV) in vitro. Cell Research, 30(3), $269-271$. doi:10.1038/s41422-020-0282-0.

[11] Colson, P., Rolain, J.-M., \& Raoult, D. (2020). Chloroquine for the 2019 novel coronavirus SARS-CoV-2. International Journal of Antimicrobial Agents, 55(3), 105923. doi:10.1016/j.ijantimicag.2020.105923.

[12] Huang, W.-H., Teng, L.-C., Yeh, T.-K., Chen, Y.-J., Lo, W.-J., Wu, M.-J., Chin, C.-S., Tsan, Y.-T., Lin, T.-C., Chai, J.-W., Lin, C.-F., Tseng, C.-H., Liu, C.-W., Wu, C.-M., Chen, P.-Y., Shi, Z.-Y., \& Liu, P.-Y. (2020). 2019 novel coronavirus disease (COVID-19) in Taiwan: Reports of two cases from Wuhan, China. Journal of Microbiology, Immunology and Infection, S1684118220300372. doi:10.1016/j.jmii.2020.02.009.

[13] Lai, C.-C., Shih, T.-P., Ko, W.-C., Tang, H.-J., \& Hsueh, P.-R. (2020). Severe acute respiratory syndrome coronavirus 2 (SARS-CoV-2) and coronavirus disease-2019 (COVID-19): The epidemic and the challenges. International Journal of Antimicrobial Agents, 55(3), 105924. doi:10.1016/j.ijantimicag.2020.105924. 


\section{Appendix I: Questionnaires}

\section{Kindly select one that most apply to you:}

1. Gender
a. Male
b. Female

2. Country of Origin

3. Age
a. $18-20$
b. $21-30$
c. $31-40$
d. $41-50$
e. $51-60$
f. 60 and above

4. Religion
a. Muslim
b. Christian
c. Tradition/Others

5. Educational Background
a. Elementary, Junior/High School
b. Undergraduate Degree
c. Post-graduate Education

6. Marital Status
a. Married
b. Single
c. Co-habitation/Relationship

7. Will you consider yourself as having attained Higher Education?
a. Yes
b. No

8. Occupational Status
a. Employed
b. Unemployed

9. Is your Occupation Related to Human Health?
a. Yes
b. No

10. Does your occupation, work, activity involves either travelling, mingling in a crowd or speaking to large number of people
a. Yes
b. No

11. Do you have any underlying medical condition or comorbidity?
a. Yes
b. No 
Kindly indicate your agreement to the following statements about Coronavirus:

1. Hand Sanitizer does kill coronavirus
a. Agree
b. Disagree
c. Neutral (No Idea)

2. Corona Virus only affect the elderly
a. Agree
b. Disagree
c. Neutral (No Idea)

3. A face mask will protect you from the virus
a. Agree
b. Disagree
c. Neutral (No Idea)

4. Dogs can get corona Virus
a. Agree
b. Disagree
c. Neutral (No Idea)

5. We should be worried about the Virus because it is deadly
a. Agree
b. Disagree
c. Neutral (No Idea)

6. There is a Vaccine for the Corona Virus
a. Agree
b. Disagree
c. Neutral (No Idea)

7. Homemade remedies can cure coronavirus
a. Agree
b. Disagree
c. Neutral (No Idea)

8. The flu is more dangerous than the novel coronavirus
a. Agree
b. Disagree
c. Neutral (No Idea)

9. People of Asian descent are more likely to be infected and spread it
a. Agree
b. Disagree
c. Neutral (No Idea)

10. The corona Virus was deliberately engineered in the lab
a. Agree
b. Disagree
c. Neutral (No Idea) 
11. The virus can be transmitted in Chinese food and packages.
a. Agree
b. Disagree
c. Neutral (No Idea)

12. Sneezing into the elbow is recommended and a good way to reduce the chance of spreading
a. Agree
b. Disagree
c. Neutral (No Idea)

13. Drying the hands with a Hand dryer helps to prevent the virus from spreading
a. Agree
b. Disagree
c. Neutral (No Idea)

14. The Virus does not Survive in hot and humid weather
a. Agree
b. Disagree
c. Neutral (No Idea)

15. You can catch the virus through mosquito bites
a. Agree
b. Disagree
c. Neutral (No Idea)

16. Antibiotics are effective for Treatment
a. Agree
b. Disagree
c. Neutral (No Idea)

17. Eating Garlic could help Fight the Virus
a. Agree
b. Disagree
c. Neutral (No Idea) 